Dev Dyn. Author manuscript; available in PMC 2016 September 13.

Published in final edited form as:

Dev Dyn. 2009 October ; 238(10): 2680-2687. doi:10.1002/dvdy.22081.

\section{Abnormal Retinal Development in the Btrc Null Mouse}

\author{
Mark Baguma-Nibasheka and Boris Kablar ${ }^{\star}$ \\ Department of Anatomy and Neurobiology, Dalhousie University Faculty of Medicine, Halifax, \\ Canada
}

Abstract

Previous microarray analysis revealed beta-transducin repeat containing (Btrc) down-regulation in the retina of mouse embryos specifically lacking cholinergic amacrine cells (CACs) as a result of the absence of skeletal musculature and fetal ocular movements. To investigate the role of Btrc in the determination of retinal cell fate, the present study examined retinal morphology in Btrc-/mouse fetuses. The Btrc-/- retina showed a normal number of cell layers and number of cells per layer with normal cell proliferation and apoptosis. However, there was a complete absence of CACs and a decrease in tyrosine hydroxylase-expressing amacrine cells. The population of other amacrine cell subtypes was normal, whereas that of the precursor cells was decreased. There was also a reduction in the number of retinal ganglion cells, whereas their progenitors were increased. These findings suggest a role for Btrc in regulating the eventual ratio of resulting differentiated retinal cell types.
\end{abstract}

\title{
Keywords
}

Btrc mutant mouse; retinal differentiation; amacrine cells; beta-TrCP

\section{INTRODUCTION}

The differentiation of the mammalian retina is subject to various intrinsic and extrinsic factors that determine the fate of individual progenitor cells and the precise ratios of the resulting cell types. Many studies have particularly implicated the progenitor cells' genetic identity in this process (Dyer and Cepko, 2000; Marquardt et al., 2001; Dyer et al., 2003; Li et al., 2004; de Melo et al., 2005, Fujitani et al., 2006), whereas others have demonstrated a distinct influence by the environment as well. Specifically, Belliveau and Cepko (1999) and Cepko (1999) revealed that the cellular microenvironment affects the specification of retinal progenitor cell fate, and previous work in our laboratory showed that mechanical forces also affect retinal morphogenesis and cell diversity (Kablar, 2003). The retina of Myf5-/-:MyoD -l- mouse embryos, which, due to the lack of striated muscle, exhibit no fetal ocular movements (FOMs), was found to have disturbances in the number of amacrine and ganglion cell types and subtypes and their precursors. In particular, in the retina of these amyogenic embryos, there was a complete absence of cholinergic amacrine cells (CACs) (Kablar, 2003), known to be important in potentiating the response of retinal ganglion cells

*Correspondence to: Boris Kablar, Department of Anatomy and Neurobiology, Dalhousie University Faculty of Medicine, 5850 College Street, Halifax, NS, Canada B3H 1X5. bkablar@dal.ca. 
(RGCs) to moving stimuli (He and Masland, 1997, Yoshida et al., 2001). Since the signal transduction pathways translating mechanical stimuli to meaningful molecular instructions for terminal retinal cell differentiation are still unclear, we subsequently used microarray analysis to help identify genes that might be important in the regulation of CAC differentiation for the functional maturation of the visual system and its eventual ability to perform motion vision. That analysis revealed a down-regulation of several genes, including beta-transducin repeat containing (Btrc), in the retina of the amyogenic embryos (BagumaNibasheka et al., 2006).

Btrc encodes the beta-transducin repeat containing protein $(\beta-\operatorname{TrCP})$, a member of the E3 ubiquitin ligase family of proteins that contain F-box and WD40 repeats (Maniatis, 1999; Kipreos and Pagano, 2000; Jin et al., 2004). As subunits of the Skip1/Cullin/F-box (SCF) enzyme complex, F-box proteins are required for the conjugation of ubiquitin to the lysine residues of particular intracellular proteins, thereby targeting those proteins as substrates for lysis by the 26S proteasome (Koepp et al., 1999; Kipreos and Pagano, 2000; Cardozo and Pagano, 2004; Ang and Wade Harper, 2005; Petroski and Deshaies, 2005). Numerous studies have shown that, by promoting the catabolism or processing of a broad range of proteins and transcription factors at specific stages of the cell cycle, the $\mathrm{SCF}^{\beta-\operatorname{TrCP}}$ complex is involved in the control of such diverse processes as: (1) chromosome stabilization (REST; Guardavaccaro et al., 2008), (2) mitotic progression (Cdc25a, Emi1, and Bora; Busino et al., 2003; Margottin-Goguet et al., 2003; Seki et al., 2008), (3) cell proliferation and apoptosis (Shh and IkappaB; Jensen and Wallace, 1997; Hatakeyama et al., 1999; Hattori et al., 1999; Winston et al., 1999), (4) cell-autonomous circadian oscillation (PERIOD2; Guardavaccaro and Pagano, 2006; Reischl et al., 2007), and (5) embryonic patterning (Gli3; Wang and Li, 2006), as well as, (6) cell adhesion and decidualization ( $\beta$-catenin; Kitagawa et al., 1999; Herington et al., 2007; Seki et al., 2008).

Btrc is known to be overexpressed and oncogenic in epithelial tumors (Saitoh and Katoh, 2001, Kudo et al., 2004, Noubissi et al., 2006), a fact that may relate to its crucial involvement in the control of intracellular levels of the tumor suppressor REST (Westbrook et al., 2008). The absence of $\beta$-TrCP, on the other hand, leads to chromosome misalignment, hyperploidy, and increased apoptosis (Guardavaccaro et al., 2003, Nakayama et al., 2003) and, in vivo, to impaired spermatogenesis and defective mammary gland development (Guardavaccaro et al., 2003, Kudo et al., 2004).

Interestingly, in a cDNA microarray analysis of gene expression in the retina of mouse embryos specifically lacking CACs as a result of the absence of skeletal musculature and consequently of FOMs, we found that Btrc mRNA was 5-fold down-regulated in the amyogenic embryos (Baguma-Nibasheka et al., 2006). Furthermore, perhaps because it facilitates the degradation of REST and Shh (which, according to Chong et al., 1995 and Ingham and McMahon, 2001, may inhibit neuronal gene expression programs), $\beta$-TrCP has been shown to be essential for proper final differentiation of neurons (West-brook et al., 2008). It is, therefore, conceivable that the Btrc gene and/or its protein product $\beta$-TrCP might play some role in regulating the pattern of cell differentiation and the consequent functional maturation of the retinal neuronal cell types. In this study, therefore, we examined the retina of Btrc-/- mouse at the end of gestation, where our previous research on retinal 
dysplasia due to the absence of FOMs has revealed differences from normal retinal development.

\section{RESULTS}

\section{Spatial Organization of the Retinal Layers Is Not Affected by the Btrc Null Mutation}

To investigate the effect of Btrc deletion on the formation of retinal layers and the generation of the correct cell numbers within those layers, we examined the basic laminar organization in hematoxylineosin stained meridional sections of the retina. An inner limiting membrane was identifiable on the inner surface of the retina in both the control wild-type embryos and their Btrc-/- littermates (Fig. 1), and the neural retina was clearly delineated into the inner and outer nuclear (or neuroblastic) layers (INL and ONL, respectively; Fig. 1). At this stage, neural retina still consists of only two nuclear layers, but, in a day or two, it will clearly consist of three nuclear layers (ganglion cell layer or GCL, INL, and ONL). ONL is destined to form primarily the photo-receptors, while INL is destined to form principally the ganglion cells (Kaufman, 1999). The outer surface of the retina was lined by the retinal pigment epithelium (RPE), with normal melanin pigmentation in the RPE of both the controls and the Btrc-/- mutants (Fig. 1B). The spatial differentiation of the retinal neuroblastic layers was similar in the two embryo types, and cell counts in the INL and ONL of the mutants were, respectively, $14.9 \pm 1.3$ and $56.0 \pm 3.9$ (mean \pm SEM of cells per field). These were not significantly different $(P<0.05)$ from the $18.4 \pm 1.6$ and $63.9 \pm 2.5$, respectively, counted in the wild-type INL and ONL (Table 1). TEM analysis also revealed that the retinal photoreceptor cells and their synapses to the RPE were similar in the wild-types and the Btrc -l- mutants (Fig. 2). Taken together, these data indicate that deletion of the Btrc gene has no recognizable effect on the embryonic retina's basic spatial organization.

\section{Cholinergic Amacrine Cells Are Absent From the Btrc-/- Retina}

Because the Btrc gene was found to be down-regulated in our previous microarray analysis of the retina in mouse embryos specifically lacking CACs as a result of the absence of skeletal musculature and consequently of FOMs, we also assessed the status of CACs in the Btrc-deletion mutant retina. As seen in Figure 2, cells of the typical "starburst-like" type characterized by cytoplasm elongated toward the vitreous body and containing numerous organelles (Kablar, 2003) were clearly evident under the TEM in the INL of the wild-type retina. However, no such cells could be identified in the Btrc-/- mutant (Fig. 2). In addition, immunohistochemistry for acetylcholinesterase (AChE) indicated the presence of AChEpositive cells in the INL of the wild-type retina but not in the mutant retina (Fig. 3). Similarly, we were unable to identify CACs employing either AChE histochemistry or immunohistochemistry for choline acetyltransferase (ChAT) (Kablar, 2003; and data not shown). These data indicate a necessity for Btrc in the CAC differentiation process.

\section{Reduced Tyrosine Hydroxylase-Expressing Amacrine Cell Count in the Btrc-/- Retina}

To further investigate the effect of Btrc deletion on amacrine cell differentiation, a count of the other amacrine cell subtypes was made in the INL after immunostaining with specific antibodies against calretinin (CR), calbindin (CB), parvalbumin (PV), and tyrosine hydroxylase (TH), (Fig. 4 and Table 1). The population of CR-expressing cells, which 
normally make up $17 \%$ of all amacrine cells (Dyer and Cepko, 2001), was similar in the control and mutant retina ( $5.8 \pm 0.5$ versus $4.6 \pm 0.4$ cells per field, respectively; Fig. 4A,B; Table 1). CB-expressing cells, which make up 9\% of amacrine cells (Dyer and Cepko, 2001), also did not differ significantly in number in wild-type and mutant retina ( $3.9 \pm 0.2$ versus $3.3 \pm 0.6$, respectively; Fig. 4C,D; Table 1). Similarly, PV-expressing amacrine cells, which normally comprise $13 \%$ of the total amacrine cell count (Dyer and Cepko, 2001), had an equal number in the control and the Btrc-/- retina ( $4.4 \pm 0.4$ versus $3.4 \pm 0.4$, respectively; Fig. 4E,F; Table 1). The Btrc-/- retina, however, showed a deficit in THexpressing cells, which normally comprise only about $0.5 \%$ of the amacrine total. Whereas the wild-type retina had a count of $1.0 \pm 0.09$ cells per field, the mutant retina had the significantly lower $(P<0.05)$ count of $0.6 \pm 0.09$, (Fig. 4G,H; Table 1).

\section{The Btrc-/- Retina Exhibits a Reduction in Retinal Ganglion Cell Population}

Next, we attempted to establish whether the absence of Btrc might affect RGC differentiation. For this, the retina was stained for Islet $1 / 2$ and, as shown in Figure $4 \mathrm{I}$ and $4 \mathrm{~J}$, the number of Islet $1 / 2$-expressing cells was significantly lower in the mutant retina than in the wild-type ( $9.2 \pm 0.7$ versus $12.3 \pm 0.7$, cells per field, respectively; Table 1$)$, suggesting that Btrc might indeed be involved in RGC differentiation. At the same time, this result indicates the involvement of Btrc in CAC differentiation, considering that Islet-1 is also present in CACs and controls their differentiation (Elshatory et al., 2007).

\section{Btrc Deletion Reduces Amacrine Progenitor Cell Counts}

To determine what effect Btrc deletion might have on the progenitors of amacrine cells, a count of these cells was made after staining for the amacrine cell precursor proteins syntaxin and VC1.1 (HNK-1/N-CAM). Syntaxin- and VC1.1-positive progenitor cells were found to give rise to amacrine and horizontal interneurons and rods (Barnstable et al., 1985), making these markers less optimal. In fact, the markers used in this and the following section of the study are not exclusively expressed in the cells of interest, because they label other cells that are biased but not yet committed to the certain cell fate, hindering the investigation of this issue. As depicted in Figure 5, syntaxin and VC1.1 are detectable in both the INL and the ONL, and whereas the number of syntaxin-expressing amacrine precursor cells was similar for the INL ( $4.4 \pm 0.6$ cells per field in the mutant and $5.1 \pm 0.2$ in wild-type), it was found to be significantly reduced in the mutant ONL (12.4 \pm 1.4 versus $20.4 \pm 0.5$, respectively; Fig. 5A,B; Table 1). In addition, there was a significantly lower number of VC1.1expressing amacrine precursor cells in the Btrc-/- retina as compared to the wild-type in both the INL ( $6.8 \pm 0.3$ versus $10.3 \pm 1.1$ cells per field) and the ONL $(24.1 \pm 2.2$ versus $32.0 \pm 1.5$; Fig. 5C,D; Table 1).

\section{Augmented Retinal Ganglion Cell Precursor Counts in Btrc-/- Mutants}

Having also noted a reduction in the number of RGCs, we subsequently stained for the RGC progenitor cell protein nestin. Nestin is a general marker for neuronal progenitor cells (Tropepe et al., 2000) and is employed here because it is expressed by the RGC precursors (Waid and McLoon, 1998). The resulting count showed that the number of nestin-expressing cells was significantly higher for both neuroblastic layers in the mutants as compared to 
controls $(6.2 \pm 0.8$ versus $3.6 \pm 0.2$ cells per field respectively for INL, and $20.0 \pm 2.1$ versus $13.8 \pm 0.2$ for ONL; Fig. 5E,F; Table 1).

\section{The Btrc-Deletion Mutant Depicts Normal Retinal Cell Proliferation and Apoptosis}

In an attempt to elucidate the possible processes underlying the observed differences in the population of various retinal cell types in the Btrc mutant retina, we also analyzed retinal cell proliferation and programmed cell death (apoptosis). However, we were not able to detect any cells immunopositive for proliferating cell nuclear antigen (PCNA) in any of the sections examined from either the control or the mutant retina (Fig. 6A,B). In addition, after immunostaining for activated caspase-3 (which indicates apoptotic cells), although a few occasional cells were visible on some sections, the staining appeared very low and was not perceptibly different between the wild-type and the mutant retina (Fig. 6C,D). Importantly, the current findings are consistent with our previous cell proliferation/death data (Kablar, 2003).

In summary, our results indicate that, despite having no apparent effect on basic spatial organization, cycle kinetics, or cell survival in the retina at this stage of development, by some as yet unspecified mechanism the absence of Btrc affects progenitor cell competence and the eventual ratio of the resulting differentiated amacrine cells as well as the amount of retinal ganglion cells.

\section{DISCUSSION}

The aim of this work was to provide a follow-up to our previously performed microarray experiments, where we found Btrc to be strikingly down-regulated in retinas that lack CACs (Baguma-Nibasheka et al., 2006). As previously stated, CACs are responsible for motion vision and directional selectivity (Yoshida et al., 2001 and references therein). The neural retinas of muscleless term fetuses do not contain any CACs (Kablar, 2003, and references therein). Whether this is an example of cell differentiation being dependent on its function, or simply a coincidence, we do not know at this point, and we could not address it more directly than we already have (Kablar, 2003), unless we were provided with another mouse mutant without extraocular musculature and examined its neural retina. For instance, Pitx2 nulls apparently specifically lack the extraocular muscles and they are viable at term (Diehl et al., 2006), therefore representing an ideal occasion for testing our hypothesis.

In the meantime, we used the opportunity provided by the retinas from muscleless fetuses to assess the differences in gene expression pattern between the control and the mutant retinas employing $15 \mathrm{~K}$ mouse cDNA microarray slides from the Ontario Cancer Institute (BagumaNibasheka et al., 2006). This way, otherwise inaccessible CACs have been assessed for the differences in gene expression, and the profile of genes obtained after the systematic subtractive microarray analysis approach (SSMAA) revealed some molecular players relevant to the differentiation of CACs. Our analysis discovered two molecules whose mouse mutants lack CACs: adapter-related protein complex 3, $\delta 1$ subunit (Ap3 $\delta I)$ and $\beta$ transducin repeat containing (Btrc) (Baguma-Nibasheka and Kablar, unpublished data). 
In fact, the Btrc-/- retina showed a normal number of cell layers and number of cells per layer with normal cell proliferation and apoptosis. However, there was a complete absence of CACs and a decrease in tyrosine hydroxylase-expressing amacrine cells. The population of other amacrine cell subtypes examined was similar to that in the wild-type retina, whereas that of the amacrine precursor cells was decreased. There was also a reduction in the number of retinal ganglion cells, whereas their progenitors were increased.

A possible mechanism of action of Btrc could be via the cell cycle machinery. As mentioned earlier, numerous studies have shown that, by promoting the catabolism or processing of a broad range of proteins and transcription factors at specific stages of the cell cycle, the $\mathrm{SCF}^{\beta-\operatorname{TrCP}}$ complex is involved in the control of mutually very diverse processes, and in particular in the mechanisms of cell proliferation and apoptosis (Shh and IkappaB; Jensen and Wallace, 1997; Hatakeyama et al., 1999; Hattori et al., 1999; Winston et al., 1999), as well as the embryonic patterning (Gli3; Wang and $\mathrm{Li}, 2006$ ). It is, therefore, possible that by destroying the proteins that positively regulate cell proliferation, Btrc causes cell differentiation to begin. Hence, in the absence of Btrc, in Btrc null mice, some cell types, which primarily depend on Btrc for their terminal functional maturation, will not differentiate, and that apparently includes CACs.

Unfortunately, the $A p 3 \delta 1$ mutants are not going to be very useful for further studies of CACs function, because they become blind soon after birth (Qiao et al., 2003). However, the Btrc nulls are viable and not blind (Nakayama et al., 2003) and, therefore, represent a model for further motion vision and directional selectivity studies, employing various approaches (e.g., electrophysiology, behavioral studies, etc.).

Additionally, via our previous microarray analysis (Baguma-Nibasheka et al., 2006) two more genes have been identified, and their knockout mice are in the EUCOMM-KOMTNORCOMM pipeline (protein sorting nexin 17 or Snx 17 and WD repeat domain 5 or $W d r 5$ ), providing an opportunity to study the function of $S n x 17$ and $W d r 5$ in CAC development in a conditional manner. Finally, all the identified molecules (and especially Ap381 and Btrc, since their mouse mutants revealed the lack of CACs) could also serve as specific markers for CACs, opening a large variety of possibilities to study the development and function of CACs in vivo, for those belonging to the field of retinal neurobiology.

\section{EXPERIMENTAL PROCEDURES}

\section{Animal Breeding and Sample Collection}

Homozygous Btrc-deficient fetuses were obtained by the interbreeding of heterozygous Btrc $+/-$ parents as described in Nakayama et al. (2003). All fetuses were collected by Cesarean section at embryonic day (E) 18.5 and the eyeballs immediately enucleated and processed for microscopic examination. Animal use and care were in accordance with all institutional guidelines.

\section{Immunohistochemistry and Morphometry}

Immunohistochemistry was performed as previously described (Kablar, 2003) on paraffinembedded $4 \mu \mathrm{m}$ sections. Hematoxylineosin staining followed the recommended Sigma (St. 
Louis, MO) kit protocol. Immunostaining used the following primary antibodies: Sigma mouse monoclonals against calbindin; 1:200; syntaxin, 1:500; and HNK/NCAM VC1.1, 1:2,000; Novocastra mouse monoclonals against acetyl-cholinesterase (AChE), 1:150 and tyrosine hydroxylase, 1:40; Developmental Studies Hybridoma Bank mouse monoclonals against Islet 1/2, 1:40 and nestin, 1:4; Dako mouse monoclonal against proliferating cell nuclear antigen (PCNA), 1:400 and Chemicon mouse monoclonal against parvalbumin, 1:1,000 and rabbit polyclonals against calretinin, 1:500 and activated caspase-3, 1:100. Secondary antibodies were from Zymed (amino ethyl carbazol [AEC] staining) and Molecular Probes (fluorescent staining), and hematoxylin nuclear counterstaining followed the AEC immunostains. In morphometry, the cells for each animal (3 wild-type and 3 mutant embryos) were averaged from counts in seven randomly selected $2,500 \mu \mathrm{m}^{2}$ fields on each meridional serial section (every $10^{\text {th }}$ section was considered) of the complete eyeball in the manner that is extensively described in Kablar (2003). The magnification used to count and to generate the insets was $1,000 \times$.

\section{Transmission Electron Microscopy (TEM)}

For electron microscopic analysis, eyeballs were fixed in $2.5 \%$ glutaraldehyde in $0.1 \mathrm{M}$ sodium cacodylate buffer ( $\mathrm{pH} 7.3$ ), post-fixed in $1 \%$ osmium tetroxide, and dehydrated in an ascending series of ethanol before embedding in LR White acrylic resin. The LKB ultramicrotome was used to make 100-nm-thick sections, which were then placed on 300mesh copper grids and stained with $2 \%$ aqueous uranyl acetate and lead citrate. The samples were examined in a JEOL JEM 1230 electron microscope equipped with a Hamamatsu ORCA-HR digital camera.

\section{Statistical Analysis}

The samples used for morphometric analyses were from three wild-type and three Btrc-/fetuses. The resulting counts were compared using the Student's $t$-test, with differences of $P$ $<0.05$ considered significant. Data are presented as mean \pm standard error of the mean (SEM).

\section{Acknowledgments}

Grant sponsor: Natural Sciences and Engineering Research Council of Canada; Grant number: 238726-01; Grant sponsor: Canadian Institutes of Health Research; Grant number: MOP-68823; Grant sponsor: Canada Foundation for Innovation; Grant sponsor: Dalhousie Medical Research Foundation.

We gratefully appreciate Dr. Keiko Nakayama at the Tohoku University Graduate School of Medicine, Center for Translational and Advanced Animal Research, Division of Developmental Genetics, Miyagi, Japan, for the generous gift of the mutant mice tissues. We also thank Heather E. Angka for excellent technical assistance. This work was funded by operating grants from the Natural Sciences and Engineering Research Council of Canada, the Canadian Institutes of Health Research, the Canada Foundation for Innovation, and the Dalhousie Medical Research Foundation to B.K.

\section{References}

Ang XL, Wade Harper J. SCF-mediated protein degradation and cell cycle control. Oncogene. 2005; 24:2860-2870. [PubMed: 15838520] 
Baguma-Nibasheka M, Reddy T, Abbas-Butt A, Kablar B. Fetal ocular movements and retinal cell differentiation: analysis employing DNA microarrays. Histol Histopathol. 2006; 21:1331-1337. [PubMed: 16977584]

Barnstable CJ, Hofstein R, Akagawa K. A marker of early amacrine cell development in rat retina. Brain Res. 1985; 352:286-290. [PubMed: 3896407]

Belliveau MJ, Cepko CL. Extrinsic and intrinsic factors control the genesis of amacrine and cone cells in the rat retina. Development. 1999; 126:555-566. [PubMed: 9876184]

Busino L, Donzelli M, Chiesa M, Guardavaccaro D, Ganoth D, Dorrello NV, Hershko A, Pagano M, Draetta GF. Degradation of Cdc25A by beta-TrCP during $\mathrm{S}$ phase and in response to DNA damage. Nature. 2003; 426:87-91. [PubMed: 14603323]

Cardozo T, Pagano M. The SCF ubiquitin ligase: insights into a molecular machine. Nat Rev Mol Cell Biol. 2004; 5:739-751. [PubMed: 15340381]

Cepko CL. The roles of intrinsic and extrinsic cues and bHLH genes in the determination of retinal cell fates. Curr Opin Neurobiol. 1999; 9:37-46. [PubMed: 10072376]

Chong JA, Tapia-Ramírez J, Kim S, Toledo-Aral JJ, Zheng Y, Boutros MC, Altshuller YM, Frohman MA, Kraner SD, Mandel G. REST: a mammalian silencer protein that restricts sodium channel gene expression to neurons. Cell. 1995; 80:949-957. [PubMed: 7697725]

de Melo J, Du G, Fonseca M, Gillesie LA, Turk WJ, Rubenstein JL, Eisenstat DD. Dlx1 and Dlx2 function is necessary for terminal differentiation and survival of late-born retinal ganglion cells in the developing mouse retina. Development. 2005; 132:311-322. [PubMed: 15604100]

Diehl AG, Zareparsi S, Qian M, Khanna R, Angeles R, Gage PJ. Extraocular muscle morphogenesis and gene expression are regulated by Pitx2 gene dose. Invest Ophthalmol Vis Sci. 2006; 47:17851793. [PubMed: 16638982]

Dyer MA, Cepko CL. p57 Kip2 regulates progenitor cell proliferation and amacrine interneuron development in the mouse retina. Development. 2000; 127:3593-3605. [PubMed: 10903183]

Dyer MA, Cepko CL. The p57 ${ }^{\mathrm{Kip} 2}$ cyclin kinase inhibitor is expressed by a restricted set of amacrine cells in the rodent retina. J Comp Neurol. 2001; 429:601-614. [PubMed: 11135238]

Dyer MA, Livesey FJ, Cepko CL, Oliver G. Prox 1 function controls progenitor cell proliferation and horizontal cell genesis in the mammalian retina. Nat Genet. 2003; 34:53-58. [PubMed: 12692551]

Elshatory Y, Everhart D, Deng M, Xie X, Barlow RB, Gan L. Islet-1 controls the differentiation of retinal bipolar and cholinergic amacrine cells. J Neurosci. 2007; 27:12707-12720. [PubMed: 18003851]

Fujitani Y, Fugitani S, Luo H, Qiu F, Burlison J, Long Q, Kawaguchi Y, Edlund H, MacDonald RJ, Furukawa T, Fujikado T, Magnuson MA, Xiang M, Wright CV. Ptf1a determines horizontal and amacrine cell fates during mouse retinal development. Development. 2006; 133:4439-4450. [PubMed: 17075007]

Guardavaccaro D, Pagano M. Stabilizers and destabilizers controlling cell cycle oscillators. Mol Cell. 2006; 22:1-4. [PubMed: 16600864]

Guardavaccaro D, Kudo Y, Boulaire J, Barchi M, Busino L, Donzelli M, Margottin-Goguet F, Jackson PK, Yamasaki L, Pagano M. Control of meiotic and mitotic progression by the F box protein betaTrcp1 in vivo. Dev Cell. 2003; 4:799-812. [PubMed: 12791266]

Guardavaccaro D, Frescas D, Dorrello NV, Peschiaroli A, Multani AS, Cardozo T, Lasorella A, Iavarone A, Chang S, Hernando E, Pagano M. Control of chromosome stability by the beta-TrCPREST-Mad2 axis. Nature. 2008; 452:365-369. [PubMed: 18354482]

Hatakeyama S, Kitagawa M, Nakayama K, Shirane M, Matsumoto M, Hattori K, Higashi H, Nakano H, Okumura K, Onoé K, Good RA, Nakayama K. Ubiquitin-dependent degradation of IkappaBalpha is mediated by a ubiquitin ligase Skp1/Cul 1/F-box protein FWD1. Proc Natl Acad Sci USA. 1999; 96:3859-3863. [PubMed: 10097128]

Hattori K, Hatakeyama S, Shirane M, Matsumoto M, Nakayama K. Molecular dissection of the interactions among IkappaBalpha, FWD1, and Skp1 required for ubiquitin-mediated proteolysis of IkappaBalpha. J Biol Chem. 1999; 274:29641-29647. [PubMed: 10514433]

He S, Masland RH. Retinal direction selectivity after targeted laser ablation of starburst amacrine cells. Nature. 1997; 389:378-382. [PubMed: 9311778] 
Herington JL, Bi J, Martin JD, Bany BM. Beta-catenin (CTNNB1) in the mouse uterus during decidualization and the potential role of two pathways in regulating its degradation. J Histochem Cytochem. 2007; 55:963-974. [PubMed: 17533218]

Ingham PW, McMahon AP. Hedgehog signaling in animal development: paradigms and principles. Genes Dev. 2001; 15:3059-3087. [PubMed: 11731473]

Jensen AM, Wallace VA. Expression of Sonic hedgehog and its putative role as a precursor cell mitogen in the developing mouse retina. Development. 1997; 124:363-371. [PubMed: 9053312]

Jin J, Cardozo T, Lovering RC, Elledge SJ, Pagano M, Harper JW. Systematic analysis and nomenclature of mammalian F-box proteins. Genes Dev. 2004; 18:2573-2580. [PubMed: 15520277]

Kablar B. Determination of retinal cell fates is affected in the absence of extraocular striated muscles. Dev Dyn. 2003; 226:478-490. [PubMed: 12619134]

Kaufman, MH. The atlas of mouse development. London: Academic Press; 1999.

Kipreos ET, Pagano M. The F-box protein family. Genome Biol. 2000; 1:1.3002.1-1-3002.7. [PubMed: 11178226]

Kitagawa M, Hatakeyama S, Shirane M, Matsumoto M, Ishida N, Hattori K, Nakamichi I, Kikuchi A, Nakayama K, Nakayama K. An F-box protein, FWD1, mediates ubiquitin-dependent proteolysis of beta-catenin. EMBO J. 1999; 18:2401-2410. [PubMed: 10228155]

Koepp DM, Harper JW, Elledge SJ. How the cyclin became a cyclin: regulated proteolysis in the cell cycle. Cell. 1999; 97:431-434. [PubMed: 10338207]

Kudo Y, Guardavaccaro D, Santamaria PG, Koyama-Nasu R, Latres E, Bronson R, Yamasaki L, Pagano M. Role of F-box protein betaTrcp1 in mammary gland development and tumorigenesis. Mol Cell Biol. 2004; 24:8184-8194. [PubMed: 15340078]

Li S, Mo Z, Yang X, Price SM, Shen MM, Xiang M. Foxn4 controls the genesis of amacrine and horizontal cells by retinal progenitors. Neuron. 2004; 43:795-807. [PubMed: 15363391]

Maniatis T. A ubiquitin ligase complex essential for the NF-kappaB, Wnt/Wingless, and Hedgehog signaling pathways. Gene Dev. 1999; 13:505-510. [PubMed: 10072378]

Margottin-Goguet F, Hsu JY, Loktev A, Hsieh HM, Reimann JD, Jackson PK. Prophase destruction of Emi1 by the $\mathrm{SCF}$ (betaTrCP/Slimb) ubiquitin ligase activates the anaphase promoting complex to allow progression beyond pro-metaphase. Dev Cell. 2003; 4:813-826. [PubMed: 12791267]

Marquardt T, Ashery-Padan R, Andrejeweski N, Scardigli R, Guillemot F, Gruss P. Pax6 is required for the multi-potent state of retinal progenitor cells. Cell. 2001; 105:43-55. [PubMed: 11301001]

Nakayama K, Hatakeyama S, Maruyama S, Kikuchi A, Onoé K, Good RA, Nakayama KI. Impaired degradation of inhibitory subunit of NF-kappa B (I kappa B) and beta-catenin as a result of targeted disruption of the beta-TrCP1 gene. Proc Natl Acad Sci USA. 2003; 100:8752-8757. [PubMed: 12843402]

Noubissi FK, Elcheva I, Bhatia N, Shakoori A, Ougolkov A, Liu J, Minamoto T, Ross J, Fuchs SY, Spiegelman VS. CRD-BP mediates stabilization of betaTrCP1 and c-myc mRNA in response to beta-catenin signalling. Nature. 2006; 441:898-901. [PubMed: 16778892]

Petroski MD, Deshaies RJ. Function and regulation of cullin-RING ubiquitin ligases. Nat Rev Mol Cell Biol. 2005; 6:9-20. [PubMed: 15688063]

Qiao X, Pannesi M, Seong E, Gao H, Burmeister M, Wu S. Photoreceptor degeneration and rd1 mutation in the grizzled/mocha mouse strain. Vision Res. 2003; 43:859-865. [PubMed: 12668055]

Reischl S, Vanselow K, Westermark PO, Thierfelder N, Maier B, Herzel H, Kramer A. Beta-TrCP1mediated degradation of PERIOD2 is essential for circadian dynamics. J Biol Rhythms. 2007; 22:375-386. [PubMed: 17876059]

Saitoh T, Katoh M. Expression profiles of betaTRCP1 and betaTRCP2, and mutation analysis of betaTRCP2 in gastric cancer. Int J Oncol. 2001; 18:959-964. [PubMed: 11295041]

Seki A, Coppinger JA, Du H, Jang CY, Yates JR 3rd, Fang G. Plk1- and beta-TrCP-dependent degradation of Bora controls mitotic progression. J Cell Biol. 2008; 181:65-78. [PubMed: 18378770]

Tropepe V, Coles BLK, Chiasson BJ, Horsford DJ, Elia AJ, McInnes RR, van der Kooy D. Retinal stem cells in the adult mammalian eye. Science. 2000; 287:2032-2036. [PubMed: 10720333] 
Waid DK, McLoon SC. Ganglion cells influence the fate of dividing retinal cells in culture. Development. 1998; 125:1059-1066. [PubMed: 9463352]

Wang B, Li Y. Evidence for the direct involvement of \{beta $\}$ TrCP in Gli3 protein processing. Proc Natl Acad Sci USA. 2006; 103:33-38. [PubMed: 16371461]

Westbrook TF, Hu G, Ang XL, Mulligan P, Pavlova NN, Liang A, Leng Y, Maehr R, Shi Y, Harper JW, Elledge SJ. SCFbeta-TRCP controls oncogenic transformation and neural differentiation through REST degradation. Nature. 2008; 452:370-374. [PubMed: 18354483]

Winston JT, Strack P, Beer-Romero P, Chu CY, Sledge SJ, Harper JW. The SCFbeta-TRCP-ubiquitin ligase complex associates specifically with phosphorylated destruction motifs in IkappaBalpha and beta-catenin and stimulates IkappaBalpha ubiquitination in vitro. Genes Dev. 1999; 13:270-283. [PubMed: 9990852]

Yoshida K, Watanabe D, Ishikane H, Tachibana M, Pastan I, Nakanishi S. A key role of starburst amacrine cells in originating retinal directional selectivity and optokinetic eye movement. Neuron. 2001; 30:771-780. [PubMed: 11430810] 


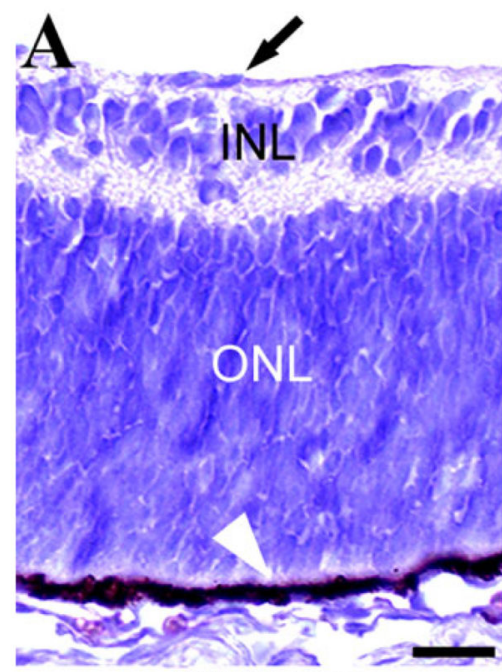

Wild-Type

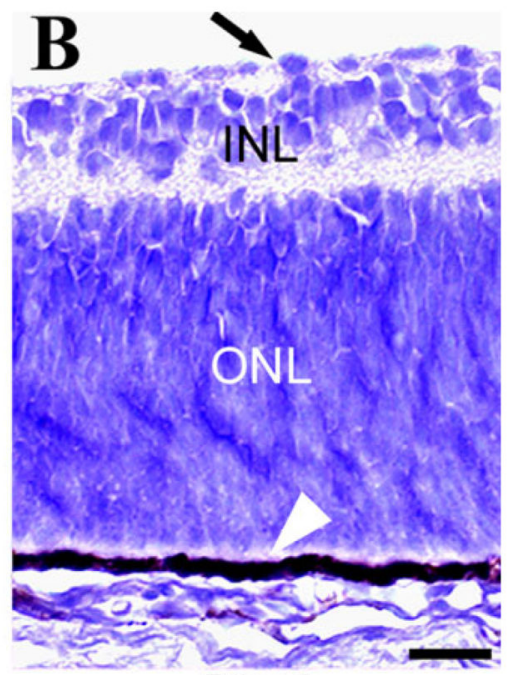

Btrc-I-

Fig. 1.

The basic spatial organization of the mutant Btrc-/- retina appears normal. On hematoxylineosin-stained paraffin-embedded sections, the inner and the outer nuclear (or neuroblastic) layers (INL and ONL, respectively) appear indistinguishable between the wildtype (A) and Btrc-/- (B) embryonic retina. Arrows indicate the retinal inner limiting membrane. Scale bar $=25 \mu \mathrm{m}$. 

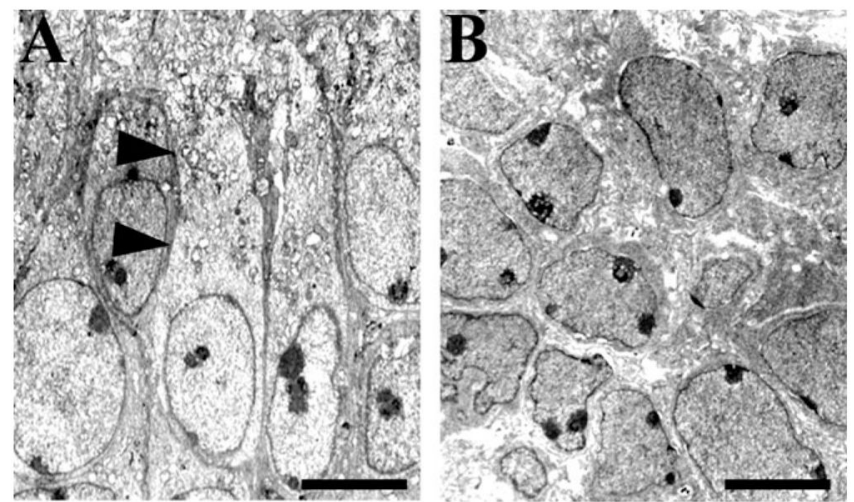

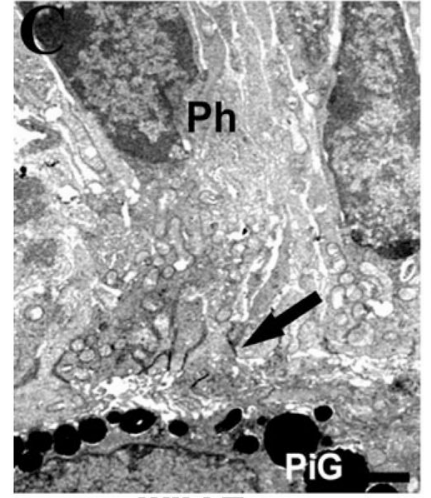

Wild-Type

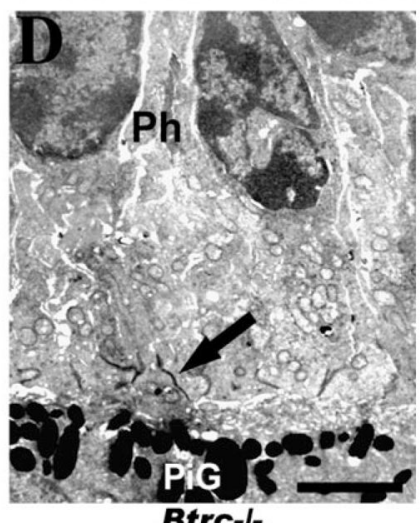

Fig. 2.

Electron microscopy reveals the absence of cholinergic amacrine cells in the Btrc-/--null retina. The "starburstlike" cell type (arrowheads) characterized by cytoplasm elongated toward the vitreous body and containing numerous organelles is identifiable in wild-type (A) but not the Btrc-/- mutant retina, where most cells appear to be undifferentiated neuroblasts (B). The morphology of the photoreceptor cells $(\mathrm{Ph})$ and their synapses with the retinal pigment epithelium (arrows in $\mathbf{C}$ and $\mathbf{D}$ ), however, was not different in the two types of retina. Note the pigment granules $(\mathrm{PiG})$ in the pigment epithelium. Scale bar $=4 \mu \mathrm{m}(\mathrm{A}, \mathrm{B})$ (original magnification, $\times 4,000)$ and $2 \mu \mathrm{m}(\mathrm{C}, \mathrm{D})(\times 8,000)$. 


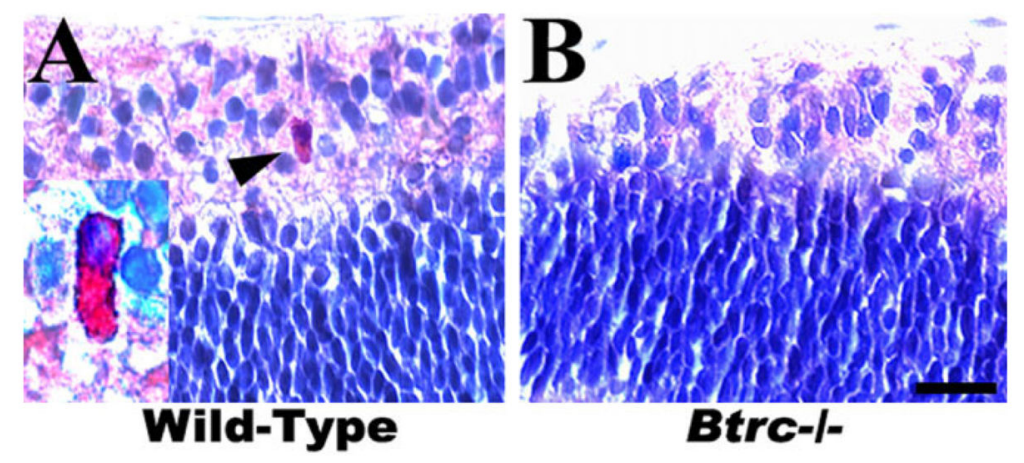

Fig. 3.

The mutant retina lacks cholinergic amacrine cells. Immuno-histochemistry indicates the presence of acetylcholinesterase-positive cells (arrowhead and inset) in the inner nuclear layer of the wild-type (A) but not the mutant retina (B). Scale bar $=25 \mu \mathrm{m}$. 

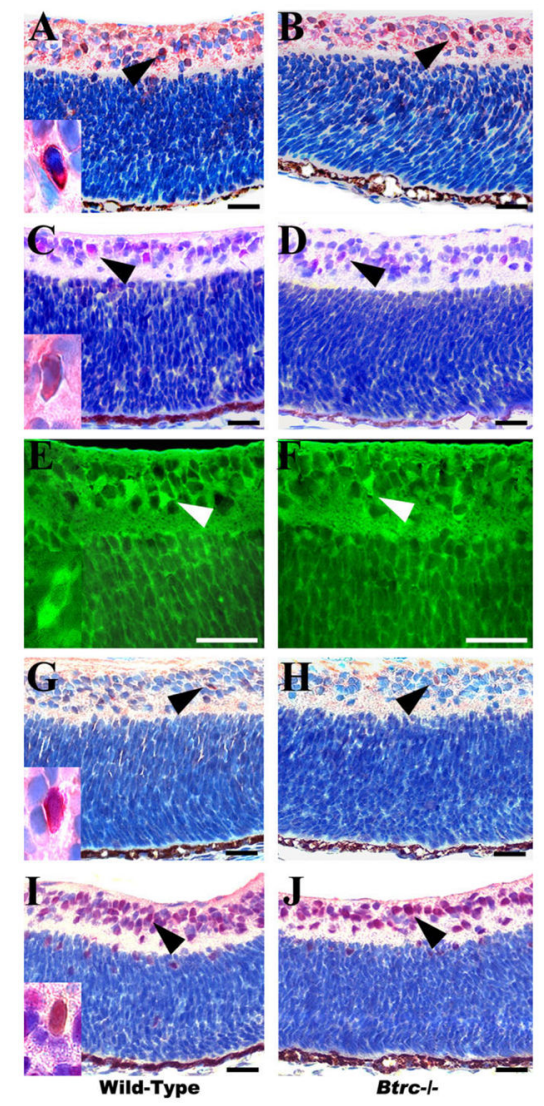

Fig. 4.

Aberrant amacrine and ganglion cell numbers in the Btrc-/- retina. Immunohistochemistry against the cytoplasmic markers calretinin $(\mathbf{A}, \mathbf{B})$, calbindin $(\mathbf{C}, \mathbf{D})$, parvalbumin $(\mathbf{E}, \mathbf{F})$, and tyrosine hydroxylase (G,H), (arrowheads) reveals a decrease in tyrosine hydroxylaseexpressing amacrine cells in the Btrc-/- retina $(\mathbf{H})$, whereas the population of other amacrine cell subtypes appears similar to that in the wild-type retina. The number of retinal ganglion cells, indicated by the nuclear marker Islet $1 / 2$, was also lower in the mutants (J) than in the wild-type (I). Insets are higher magnifications of positively stained cells. Scale bar $=25 \mu \mathrm{m}$. 

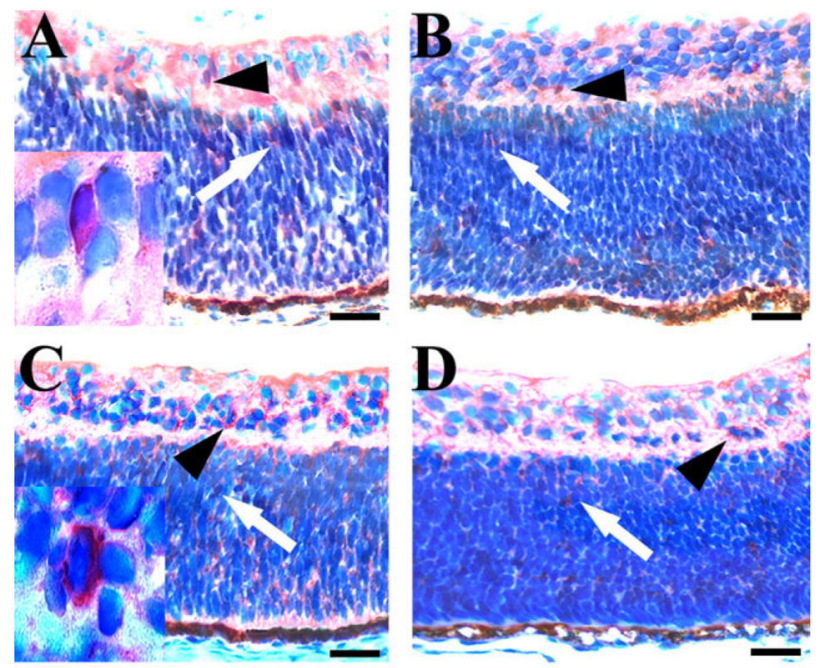

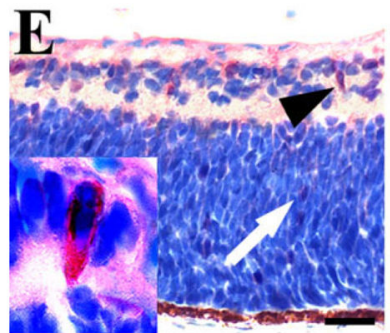

Wild-Type

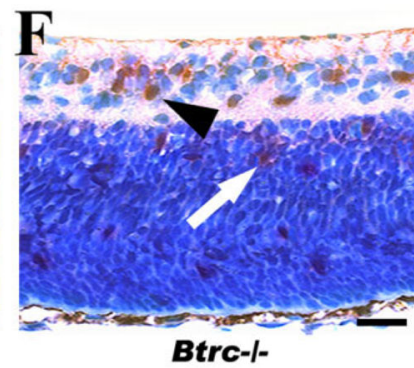

Fig. 5.

Differences in precursor cell populations in the Btrc-/- retina. The number of cells immunopositive for syntaxin was higher in the wild-type retina (A) than in the Btrc-/mutant (B), as was the case for VC1.1 (C vs. D, respectively). In contrast, the number of retinal ganglion progenitor cells, signaled by nestin staining, was lower in the wild-type (E) than in the mutants $(\mathbf{F})$. Arrowheads and arrows, respectively, indicate immunolabeled cells in the inner and outer nuclear layers. Scale bar $=25 \mu \mathrm{m}$. 

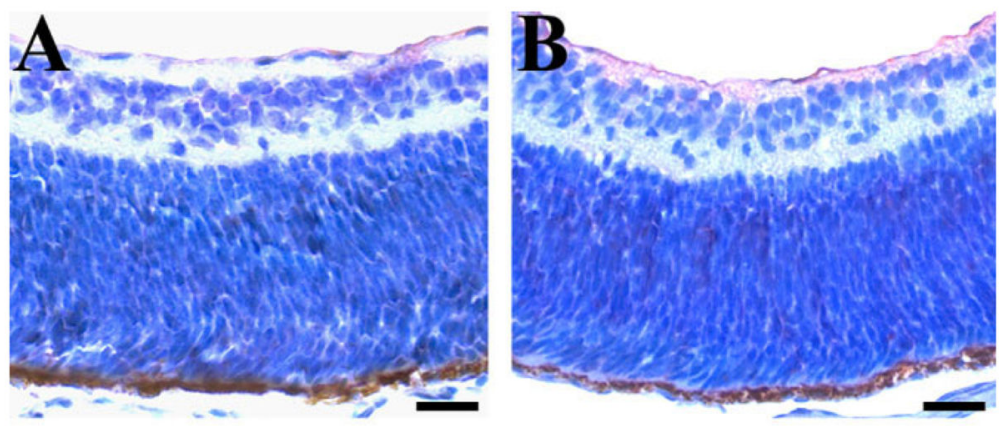

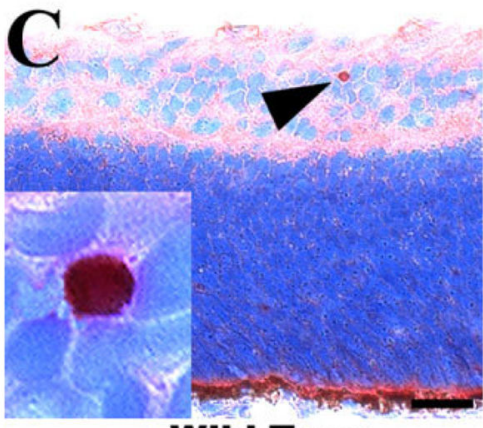

Wild-Type

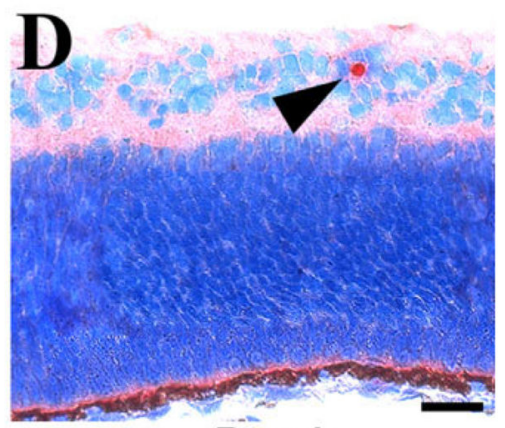

Btrc-I-

Fig. 6.

Normal cell proliferation and apoptosis in the mutant retina. Cell proliferation, indicated by immunostaining for proliferating cell nuclear antigen, appears similarly negligible in the wild-type (A) and Btrc-/- (B) retina. Similarly, staining for activated caspase-3, indicating apoptosis, was indistinguishable between the two $(\mathbf{C}$ and $\mathbf{D})$. Arrowheads and high-power inset indicate positively stained cells. Scale bar $=25 \mu \mathrm{m}$. 
TABLE 1

Neuroblastic Layer Cell Counts ${ }^{a}$ of Wild-type and Btrc-/- Retina at E18.5

\begin{tabular}{|lccc|}
\hline & & Wild-type & Btrc-/- \\
\hline Total Cell Count & Inner & $18.4 \pm 1.6$ & $14.9 \pm 1.3$ \\
Calretinin & Outer & $63.9 \pm 2.5$ & $56.0 \pm 3.9$ \\
Calbindin & Inner & $5.8 \pm 0.5$ & $4.6 \pm 0.4$ \\
Tyrosine Hydroxylase & $"$ & $1.0 \pm 0.09$ & $0.6 \pm 0.09^{*}$ \\
Parvalbumin & $"$ & $4.4 \pm 0.4$ & $3.4 \pm 0.4$ \\
Islet 1/2 & $"$ & $12.3 \pm 0.7$ & $9.2 \pm 0.7^{*}$ \\
Syntaxin & Inner & $5.1 \pm 0.2$ & $4.4 \pm 0.6$ \\
& Outer & $20.4 \pm 0.5$ & $12.4 \pm 1.4^{*}$ \\
VC1.1 & Inner & $10.3 \pm 1.1$ & $6.8 \pm 0.3^{*}$ \\
& Outer & $32.0 \pm 1.5$ & $24.1 \pm 2.2^{*}$ \\
Nestin & Inner & $3.6 \pm 0.2$ & $6.2 \pm 0.8^{*}$ \\
& Outer & $13.8 \pm 0.2$ & $20.0 \pm 2.1^{*}$ \\
\hline
\end{tabular}

${ }^{a}$ Mean \pm SEM of cells per field.

significantly different from wild-type; $p<0.05, \mathrm{n}=3$. 